\title{
A QUÍMICA NA GASTRONOMIA MOLECULAR: ENSINO DE LIGAÇÕES QUÍMICAS POR MEIO DO ENFOQUE CTS
}

Julianna Ferreira de Almeida Prata Joaquim Fernando Mendes da Silva

\section{Introdução}

O ensino CTS (Ciência, Tecnologia e Sociedade) na educação básica tem como propósito promover uma formação que possibilite aos indivíduos tomarem decisões responsáveis para a vida em sociedade com base em argumentos científicos e na análise crítica dos interesses envolvidos no desenvolvimento científico e tecnológico nas sociedades capitalistas contemporâneas. Assim, a implementação do enfoque CTS na sala de aula através dos conteúdos das disciplinas da área das Ciências da Natureza devem incluir temas de interesse social (SANTOS, 2008). Para isso, o educador deve selecionar temas que partem de questões mais gerais e busquem estabelecer vínculos com o cotidiano dos alunos.

A abordagem CTS pode utilizar diversas metodologias de ensino e aplicar estratégias que exigem a associação de campos de conhecimentos tecnológico, social, 
científico e ético, tais como palestras com especialistas, visitação a fábricas, resolução de problemas abertos, sessões de questionamentos, debates e experimentos em laboratório (FIRME; AMARAL, 2011). Os diferentes níveis de interrelação e compreensão sobre a racionalidade científica, o desenvolvimento tecnológico e a participação social podem servir de aporte para caracterizar as diversas abordagens curriculares observadas nas propostas de ensino CTS (SANTOS, 2012). Santos e Mortimer (2000) apresentam oito diferentes categorias, baseadas em uma classificação elaborada por Aikenhead (1994), onde o “conteúdo de CTS” (SANTOS; MORTIMER, 2000, p. 15) pode ser integrado às atividades didáticas desde uma simples exemplificação durante uma aula de Ciências, passando por propostas onde a contextualização dos conteúdos científicos permite o estabelecimento de interrelações com os aspectos tecnológicos e sociais, até finalmente chegar em desenhos onde o conteúdo CTS desempenha um papel estruturante do currículo escolar.

Na perspectiva do ensino de Química, a contextualização torna-se uma ferramenta importante para a formação crítica do aluno, a fim de torná-lo apto a discutir os assuntos relativos à Química que estão relacionados ao seu cotidiano. Nesse sentido, possibilita oportunidades para que ele desenvolva e manifeste seus próprios pontos de vista relacionados à análise crítica de tal realidade. Um ensino de Química e, mais amplamente, um ensino de Ciências que valoriza e aplica em sala de aula tais aspec- 
tos tem seu alicerce no movimento CTS (PALACIOS; GALBARTE; BAZZO, 2005). Para se atender a esse objetivo, é necessário ampliar a visão do processo educacional, considerando que não se podem enfatizar apenas a dimensão conceitual, mas também as dimensões procedimental e atitudinal, que servirão para a formação do indivíduo pela ampliação de seus horizontes culturais e de sua autonomia no exercício da cidadania.

Nesse contexto, a alimentação é uma temática adequada para se trabalhar dentro do enfoque CTS, pois constitui uma das atividades humanas fundamentais, abrangendo aspectos não somente biológicos, mas também outros que são fundamentais na dinâmica da evolução das sociedades, impactando nos campos econômico, social, científico, político e cultural (PROENÇA, 2010). Uma análise da evolução histórica da alimentação permite-nos observar que os recursos, os hábitos e os padrões alimentares são aspectos relevantes que colaboram com a reflexão da complexidade e da grandiosidade que transpassam as relações entre os membros de uma comunidade, assim como as relações entre diferentes sociedades (ABREU, 2001).

A alimentação pode ser explorada sob a ótica do enfoque CTS por apresentar desafios científicos e tecnológicos que se relacionam com a produção e o processamento de alimentos que, por sua vez, atendem a demandas específicas de diferentes estratos sociais. Assim, en- 
quanto as classes menos favorecidas requerem a produção de alimentos de baixo custo e ricos em carboidratos e lipídeos para a produção de energia que permita a venda de sua força laboral, as mais favorecidas demandam por experiências gastronômicas que atendam a seus interesses sociais e culturais (MONTEIRO, 2003). Apresentar essas diferentes demandas sociais, explicitando, ainda, as formas como o conhecimento científico e tecnológico é mobilizado para resolvê-las, possui o potencial de promover reflexões e debates entre os alunos da Educação Básica, de forma a construir sua criticidade e capacidade de argumentação.

A partir dessa reflexão foi proposta a elaboração de uma Sequência Didática (SD) que permitisse a articulação de conteúdos do currículo escolar de Química a essas discussões de cunho social relacionadas com o tema alimentação, em consonância com os princípios do enfoque CTS. As SD são instrumentos capazes de articular diferentes atividades ao longo de uma unidade didática através de uma sequência orientada para a realização de determinados objetivos educacionais, sendo possível, ainda, analisar as diferentes formas de intervenção do professor (ZABALA, 1998). Embora na SD elaborada tenham sido exploradas tanto a questão da fome e da sua relação com a produção de alimentos para a classe trabalhadora quanto as demandas por experiências sensoriais e culturais das classes mais favorecidas, neste artigo iremos apresentar os resultados relacionados a esta última 
questão, de forma a permitir um foco nas relações estabelecidas com o conteúdo curricular de Ligação Química.

Para explorar essa face da discussão sobre a alimentação, optou-se pela apresentação do tema Gastronomia Molecular (GM), que havia sido apontado anteriormente por alunos de uma das escolas envolvidas no projeto como um tema de interesse para as aulas de Química. Esse tema permite que o professor, nas aulas de Química, organize diferentes atividades didáticas teóricas e experimentais que correlacionem o preparo do alimento com os conteúdos dessa disciplina, possibilitando, ainda, que a GM seja abordada de forma interdisciplinar (KIKUTI; DE SOUZA; MOURA, 2018).

Segundo Gil (2010), a cozinha é um laboratório e deveria ser aproveitada nas escolas para tornar o estudo das Ciências Naturais mais atrativo para crianças e jovens através da Ciência dos Alimentos. Segundo a autora, é a partir do ensino básico que se devem promover experiências de aprendizagem diferenciadas como a experimentação, promovendo a discussão dos conteúdos presentes no currículo e aplicados ao cotidiano e ao desenvolvimento de projetos que promovam a articulação de saberes, sendo que a GM se apresenta como um tema que demanda tais experiências e articulações.

A GM estuda as transformações físico-químicas de materiais comestíveis produzidos ao preparar o ali- 
mento e seus fenômenos, onde a ciência é utilizada na otimização de novas combinações de ingredientes e novos métodos de preparação. Ingredientes originários da pesquisa em ciência e tecnologia dos alimentos, tais como hidrocolóides, enzimas e emulsionantes, são ferramentas poderosas para ajudar a produzir pratos impossíveis de serem feitos de outra forma (ABRANTES, 2014), o que fornece, ao professor, a possibilidade de discutir, a partir dos pressupostos do enfoque CTS, como demandas sociais e culturais podem fomentar pesquisas científicas e tecnológicas na área da Química, incluindo o desenvolvimento de novos materiais e processos, como aqueles envolvidos nas técnicas de esferificação.

A esferificação é uma das técnicas mais utilizadas na GM a fim de alterar a consistência de alimentos e bebidas, e envolve o processo culinário de moldar um líquido comestível que, quando submerso num banho, forma esferas que visualmente assemelham-se a ovas. A cápsula mole é geralmente uma forma de apresentação cujo interior apresenta-se na forma líquida, podendo ser preenchida também com conteúdo semissólido, pós e outros sólidos secos (ABRANTES, 2014) e que é formada a partir da interação de um polímero natural, o alginato de sódio, com íons cálcio, levando à formação de uma rede tridimensional de consistência gelatinosa e que envolve espécies químicas que apresentam tanto ligações covalentes quanto iônicas. 
Buscou-se, portanto, elaborar uma SD que além de abordar as questões socio científicas discutidas anteriormente, também fosse capaz de explorar as possibilidades das técnicas de esferificação como um recurso didático a ser acionado pelo professor de Química para trabalhar o tema Ligações Químicas com alunos de primeiro ano do Ensino Médio. Nesta SD são utilizados vídeos, debates, aulas expositivas e dialogadas, além de uma atividade experimental envolvendo essas técnicas características da GM.

\section{Metodologia}

O planejamento da SD teve como base as relações entre aspectos científicos, tecnológicos e sociais relacionados ao tema Ligação Química, conforme pode ser observado na Figura 1. Optou-se, a partir disso, pelo desenvolvimento da SD de forma que se adequasse a uma proposta curricular CTS do tipo 3 na classificação de Aikenhead (SANTOS; MORTIMER, 2000, p. 15), ou seja, "pela incorporação sistemática do conteúdo de CTS ao conteúdo programático”. Nesta categoria, os estudos CTS são incorporados aos conteúdos curriculares como uma sequência de pequenos estudos organizados ao redor de um tema unificador. Assim, fica clara a centralidade da aprendizagem dos conceitos relacionados ao tema Ligação Química na proposta metodológica da SD. 
Figura 1. Fluxograma da interação dos aspectos da abordagem CTS aos conteúdos de ligações químicas.

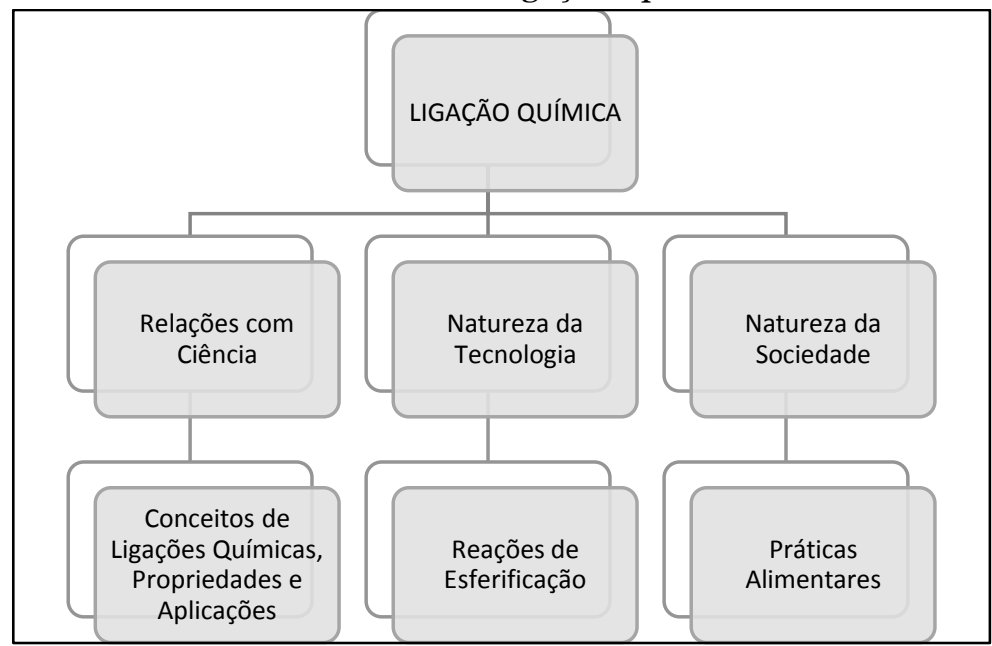

Fonte: Autoria Própria.

A SD se dividiu em três momentos, conforme pode ser observado na Figura 2.

Figura 2. Fluxograma do desenvolvimento da SD.

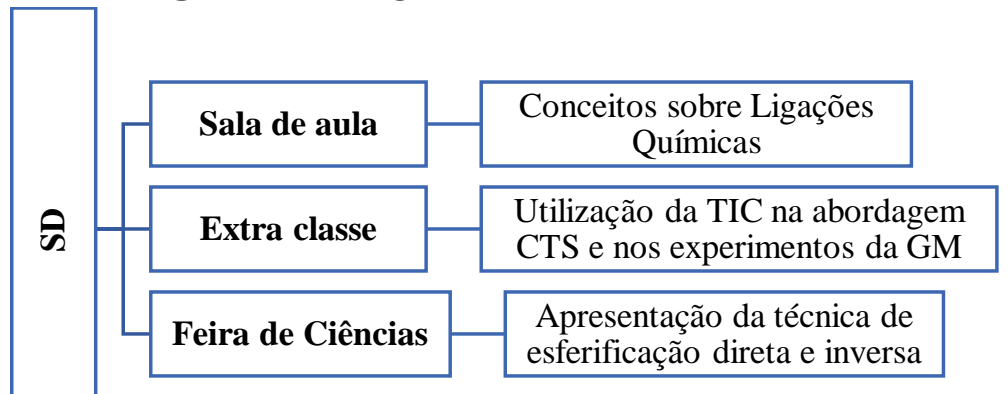

Fonte: Autoria própria. 
No primeiro momento, realizado em sala de aula e com a mediação da professora pesquisadora por dois meses, foram abordados os conceitos sobre ligações químicas. O segundo momento foi realizado sob a forma de atividades extra classe, quando o aplicativo WhatsApp foi utilizado por um mês para a exibição e discussão dos vídeos propostos e para a discussão sobre a técnica de esferificação. O último momento constituiu-se na apresentação dos alunos em uma Feira de Ciências, quando estes realizaram experimentalmente a esferificação direta e inversa de diferentes preparações alimentícias, sendo os produtos oferecidos para consumo a docentes e discentes que visitavam a feira (Figura 3).

Figura 3. Apresentação das técnicas de esferificação na Feira de Ciências.

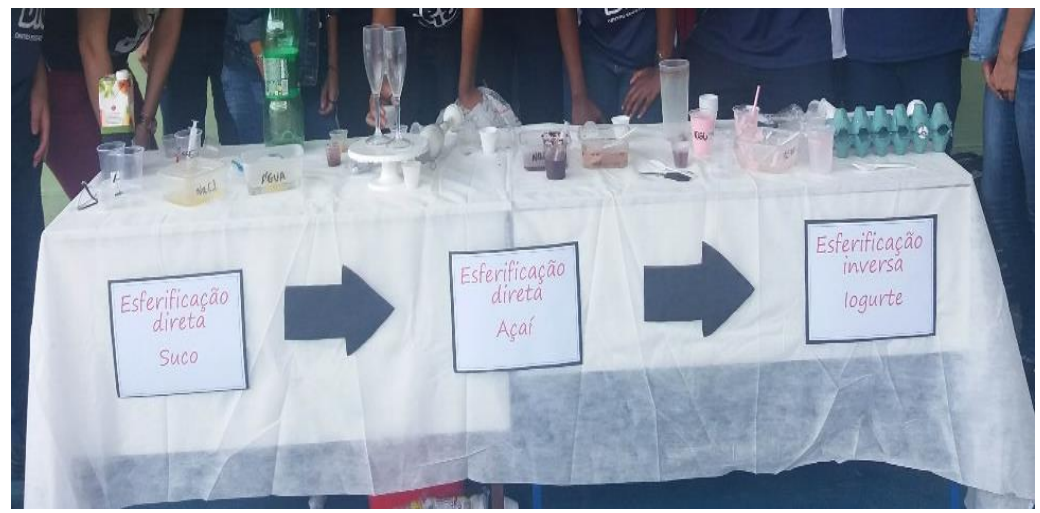

Fonte: Autoria própria.

A inclusão da Feira de Ciências à proposta da SD está em sintonia com os pressupostos relacionados à di- 
vulgação científica e tecnológica como ferramenta para uma educação baseada no enfoque CTS (VALÉRIO; BAZZO, 2006). Os alunos participaram desta atividade dividindo a apresentação em cinco etapas sequenciais: (I) Apresentação da GM; (II) Esferificação direta utilizando suco industrializado; (III) Esferificação direta utilizando açaí com guaraná; (IV) Esferificação inversa utilizando iogurte; e (V) Explicação do processo de formação do gel.

Os momentos supracitados da SD foram trabalhados ao longo de nove aulas, conforme descrito na Figura 4 .

Figura 4. Programação das aulas da Sequência Didática
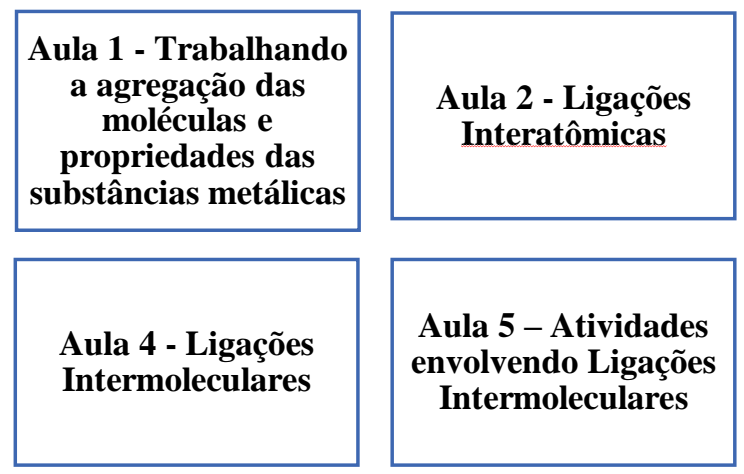

Aula 7 - Explicação do experimento e revisão dos conteúdos
Aula 5 - Atividades envolvendo Ligações Intermoleculares

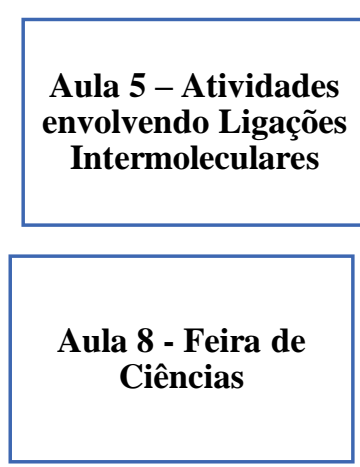

Fonte: Autoria própria.
Aula 3 - Atividades envolvendo Ligações Interatômicas

Aula 6 - Geometria Molecular e atividades

Aula 9 - Avaliação formal 
Foram envolvidos, neste trabalho, alunos de duas turmas da primeira série do Ensino Médio Regular de uma instituição privada, no período diurno, na zona oeste da cidade do Rio de Janeiro, totalizando 13 alunos com idades entre 14 e 16 anos. Para a aplicação da SD para este público alvo, foi proposto o uso de uma hora e 40 minutos de trabalho semanal nas aulas de Química durante dois meses no $2^{\circ}$ bimestre de 2018.

Para o auxílio no cumprimento da sequência foi utilizado o aplicativo WhatsApp, uma ferramenta da Tecnologia da Informação e Comunicação (TIC), a qual foi utilizada com o propósito de interagir de modo eficaz com os alunos durante algumas etapas da SD.

Segundo Martinho e Pombo (2009), as TICs podem constituir um elemento valorizador das práticas pedagógicas, já que, em termos de acesso à informação, valorizam os processos de compreensão de conceitos na medida em que conseguem associar diferentes tipos de representação de texto, imagem fixa e animada, vídeo e som. Para a aplicação de toda a metodologia proposta, essa interação foi necessária pela carga horária disponível ser pequena. Esta ferramenta pôde ser utilizada por este grupo de alunos e pela professora pesquisadora porque todos tinham acesso à internet e a um smartphone. 
Foi desenvolvida pela autora, professora de Química regente das turmas, diversas etapas distintas e inter-relacionadas, a saber:

Aula 1 - Nesta etapa inicial, pode se trabalhar a agregação das moléculas e propriedades das substâncias metálicas por meio de aula dialogada e elaborada com o apoio de imagens e dispositivo multimídia. Nesta primeira aula discutiu-se as fases de agregação no estado físico líquido, sólido ou gasoso e sua dependência da temperatura e pressão. Em um segundo momento, os alunos debateram uma questão referente à diferença do cozimento dos alimentos entre uma panela de ferro e a outra de alumínio (diferença de condutividade térmica entre elas, $\mathrm{Al}=237$ $\mathrm{W} \cdot \mathrm{m}^{-1} \cdot \mathrm{K}^{-1}$ e $\left.\mathrm{Fe}=80 \mathrm{~W} \cdot \mathrm{m}^{-1} \cdot \mathrm{K}^{-1}\right)$. Este debate teve a finalidade de introduzir o conteúdo das ligações químicas presentes nesses materiais, além de indicar que vários são os fatores que influenciam a migração dos metais do utensílio, sendo um deles a qualidade da liga metálica.

Aula 2 - Ligações Interatômicas - Aula predominantemente expositiva sobre ligações interatômicas com o uso do quadro branco.

\section{Aula 3 - Atividades envolvendo Ligações Intera- tômicas - Aula predominantemente expositiva com o uso do quadro branco na realização de exercícios de revi- são sobre interações interatômicas.}


Aula 4 - Ligações intermoleculares - Aula predominantemente expositiva sobre ligações intermoleculares com o uso do quadro branco.

\section{Aula 5 (Presencial) - Atividades envolvendo Li-} gações Intermoleculares - Aula predominantemente expositiva com o uso do quadro branco na realização de exercícios de revisão sobre interações intermoleculares.

\section{Aula 5 (Virtual) - Consumismo e Alimentação -} Aula dialogada virtualmente utilizando o aplicativo WhatsApp, com publicação de três vídeos. Um vídeo que buscou realizar uma reflexão sobre consumismo, exibindo o vídeo "HOMEM", por Steve Cutts, que retrata uma crítica ao modo de vida orientado por uma compulsão consumista, que leva o indivíduo a comprar de forma ilimitada. Faz-se uma sátira em razão do seu significado simbólico de prazer e felicidade.

O segundo vídeo publicado, intitulado "Muito além do peso" 2 , por Maria Farinha Filmes, que retrata o investimento das indústrias alimentícias, divulgando alimentos que tendem a ser ricos em gorduras, açúcar e sal, mas pobres em nutrientes. O público infantil é o mais vulnerável aos apelos promocionais de propaganda e publicidade que envolve a promoção de diversos alimentos,

${ }^{1}$ Disponível em: https://youtu.be/5XqfNmML_V4

2 Disponível em: https://youtu.be/8UGe5GiHCT4 
como biscoitos, refrigerantes, fast food e alimentos semiprontos industrializados.

E, por fim, o terceiro vídeo buscou promover uma reflexão sobre as causas da desnutrição e da fome no Brasil intitulado "A fome no Brasil"3, por Adelcio Vargas, que aborda o tema no Jornal Nacional, com intervenção da docente no grupo do WhatsApp para questionar o que os alunos pensam sobre fome e pobreza.

A partir da construção de ideias relacionadas às discussões, foi proposta a redação de um texto dissertativo-argumentativo sobre as possíveis causas de haver fome no Brasil. A professora pesquisadora propôs o estabelecimento de relações que a alimentação possui com outras disciplinas, como a Sociologia e a Biologia, dando continuidade às atividades tendo sempre em mente a abordagem de temas englobando discussões que perpassam pelas Ciências, suas Tecnologias, e suas relações com a Sociedade.

\section{Aula 6 (Presencial) - Geometria Molecular e ati-} vidades - Aula predominantemente expositiva sobre geometria molecular e polaridade das moléculas com o uso do quadro branco. Entretanto, uma atividade em grupo pode ser realizada para a fixação do conteúdo como

3 Disponível em: https://youtu.be/wVUDVV8cJ8o 
a utilização da massa de modelar para a representação das formas geométricas das moléculas.

Aula 6 (Virtual) - Gastronomia - Aula dialogada utilizando o aplicativo WhatsApp, com o compartilhamento de dois vídeos sobre gastronomia. O primeiro vídeo, "Lição de gastronomia" 4, de Maurício Ricardo Quirino, apresentou uma reflexão sobre a ingestão de batatas fritas e de outros ingredientes de origem industrial empregados no processo de sua produção, como a hidroquinona e o dimetilpolissiloxano, presentes no óleo de fritura.

Após o compartilhamento do vídeo, discutiu-se sobre a adição de ingredientes pelas indústrias alimentícias ao produto original, como proteínas, gorduras, carboidratos, sais contendo o cátion sódio e conservantes, entre outros, em muitos alimentos que fazem parte das refeições diárias. Além disso, foi discutida a relevância das pesquisas científicas realizadas nas indústrias de alimentos que defendem esses aditivos para melhora do produto, como para aumentar a durabilidade na prateleira, melhorar a aparência, evitar reações provocadas pelo meio ambiente e por bactérias ou facilitar algumas etapas da produção industrial.

4 Disponível em: https://www.youtube.com/watch?v=hql4olfF2RY 
Em seguida, apresentou-se o vídeo "Gastronomia molecular: novas sensações à mesa" 5 por Larissa Schmidt. Após a exibição do vídeo, foi discutido como a GM se ocupa do estudo e da aplicação de conhecimentos científicos durante o processo de transformação dos alimentos.

\section{Aula 7 (Presencial) - Explicação do experimento} e revisão dos conteúdos - Existem dois tipos de métodos de esferificação que se diferem pelo conteúdo de íons cálcio que o líquido a ser esferificado apresenta: a esferificação direta e a inversa. Entretanto, em ambas ocorre um processo de troca iônica entre os íons sódio presentes na estrutura do alginato de sódio e os íons cálcio adicionados na preparação alimentícia (esferificação direta) ou eventualmente já presentes nos alimentos a serem processados (esferificação inversa). No mecanismo de gelificação, portanto, ocorre a troca dos íons sódio pelos íons cálcio na proporção de 2:1 e as cadeias de alginato ligam-se entre si pelos íons cálcio, formando o gel.

Para que os alunos compreendessem a técnica de esferificação direta, foram apresentados os aditivos alimentares utilizados nessa técnica de esferificação, assim como uma representação do processo de troca iônica para a formação do gel. Para representar a estrutura do alginato de sódio foi utilizada uma fita de tecido (corresponden-

5 Disponível em: https://youtu.be/tVRLwJVP2Lw 
te à cadeia polimérica), na qual foram presos pregadores plásticos para representar os íons carboxilatos da estrutura do alginato; estes, por sua vez, estavam presos a clips na coloração amarela, que representavam os íons sódio $\left(\mathrm{Na}^{+}\right)$. Para demonstrar o processo de gelificação, os clips amarelos foram substituídos clips vermelhos, representando os íons cálcio $\left(\mathrm{Ca}^{2+}\right)$, porém agora cada clip vermelho se ligaria a dois pregadores diferentes. As Figuras 5 e 6 representam a estrutura do alginato de sódio e a formação do gel pela troca iônica, respectivamente.

Figura 5. Representação da estrutura do alginato de sódio pela fita com pregadores plásticos; para representar os íons de sódio $\left(\mathrm{Na}^{+}\right)$ foram utilizados clips de coloração amarela.

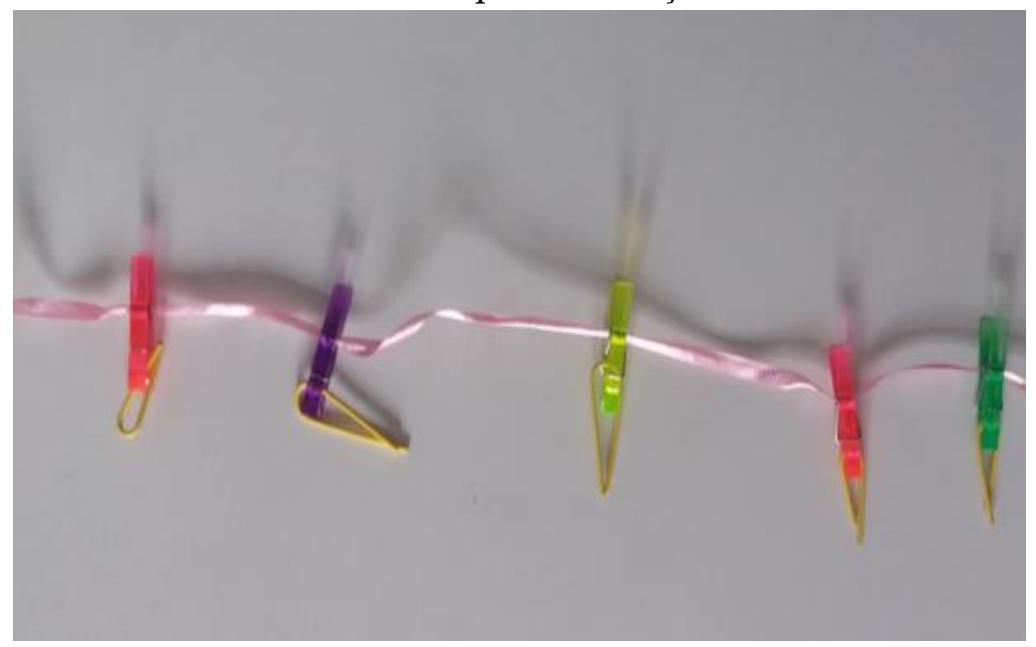

Fonte: Autoria Própria. 
Figura 6. Representação da formação das esferas após as trocas iônicas, sendo que os clips na coloração vermelha representam os íons cálcio $\left(\mathrm{Ca}^{2+}\right)$.

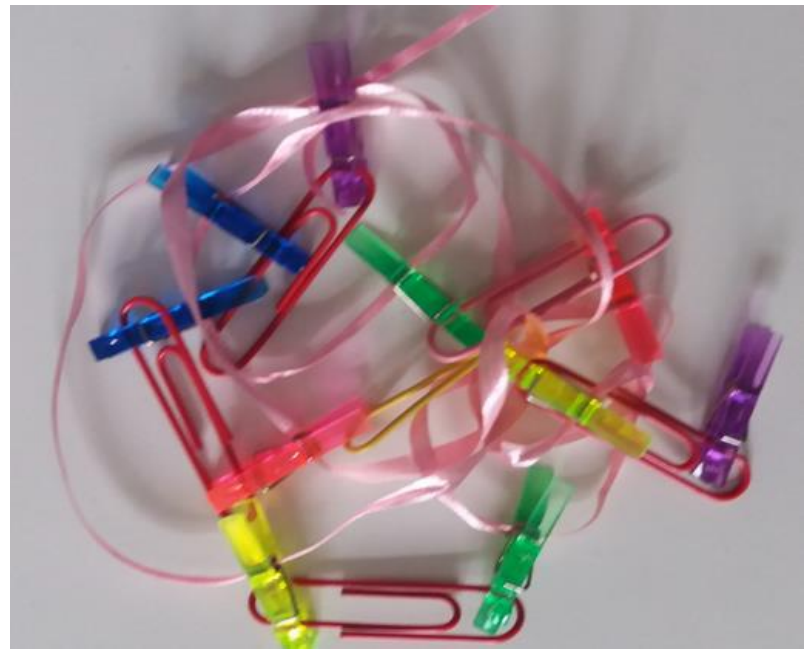

Fonte: Autoria Própria

Em seguida, as técnicas de esferificação foram demostradas aos alunos utilizando-se sucos industrializados e os aditivos alimentares alginato de sódio e cloreto de cálcio do fabricante GastronomyLab ${ }^{\circledR}$ (Figura 7). Inicialmente, dissolveu-se, com um mixer, $1 \mathrm{~g}$ de alginato de sódio em $100 \mathrm{~mL}$ do líquido a gelificar, que neste caso foi suco de manga. A seguir, dissolveu-se $1 \mathrm{~g}$ de cloreto de cálcio em $100 \mathrm{~g}$ de água filtrada. A mistura do alginato foi adicionada gota a gota, com auxílio de uma seringa, na solução aquosa de cloreto de cálcio. As esferas formadas foram coletadas com uma peneira e lavadas com água filtrada, de modo a remover o cloreto de cálcio residual e, 
assim, parar o processo de gelificação, bem como para remover o sabor amargo conferido pelos íons cálcio em excesso.

Já a demonstração da técnica de esferificação inversa consistiu em adicionar $1 \mathrm{~g}$ de gluconato de cálcio em $100 \mathrm{~mL}$ do líquido a gelificar (iogurte sabor morango). Em alguns casos, como em queijos ou iogurtes, o líquido já tem um teor de cálcio alto o suficiente para promover o processo, não sendo necessário adicionar o aditivo gluconato de cálcio. Entretanto, se a viscosidade do líquido for baixa, como no iogurte e açaí, é necessário ajustá-la com adição de $0,5 \mathrm{~g}$ de goma xantana, obtida junto ao memso fabricante já indicado anteriormente. Posteriormente, dissolveu-se, com um mixer, cerca de $1 \mathrm{~g}$ de alginato de sódio em cerca de $100 \mathrm{~mL}$ de água filtrada e essa solução foi deixada em repouso por 15 minutos num recipiente baixo e com fundo plano. Cuidadosamente foram apanhadas, com uma colher, porções do líquido a ser gelificado e transferidas para a solução contendo alginato de sódio, tendo o cuidado de que as esferas não entrassem em contato entre si. Cerca de 1 minuto depois, houve a formação de uma película resistente em torno do líquido. As esferas foram retiradas da solução e transferidas para um recipiente contendo água filtrada. 
Figura 7. Técnicas de esferificação: A. Preparação da mistura a ser gelificada; B. Preparação das esferas por esferificação direta utilizando suco industrializado de manga; C. Esferificação inversa utilizando

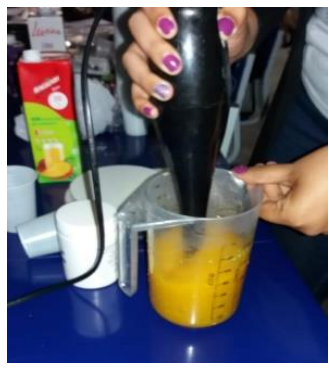

A

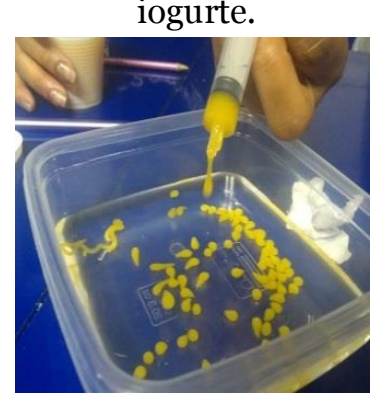

B

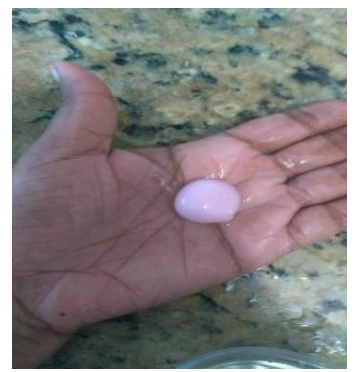

$\mathrm{C}$

Fonte: Autoria Própria

A realização desse experimento nas escolas é viável, pois pode ser realizado na sala de aula ou na cozinha. Os aditivos alimentares são de baixo custo, podendo ser adquiridos em sites gastronômicos ${ }^{6}$ e as quantidades comercializadas são suficientes para serem utilizadas em diversas atividades escolares.

Aula 8 - Feira de Ciências - foi realizada na forma de uma atividade em grupo, onde treze alunos apresentaram a GM a outros alunos e professores utilizando a técnica de esferificação. A divisão da apresentação foi realizada pelos próprios alunos de acordo com seus interesses pessoais e a apresentação do trabalho foi dividida em quatro etapas: (I) apresentação sobre a relevância da gastrono-

${ }^{6}$ https://loja.gastronomylab.com/ 
mia molecular, utilizando cartazes como material didático; (II) realização da técnica de esferificação direta, utilizando suco industrializado e polpa de açaí; (III) a esferificação inversa, usando iogurte de morango; (IV) explicação sobre a formação do gel através da troca iônica com auxílio de bolas de isopor representando os íons $\mathrm{Na}^{+} \mathrm{e}$ $\mathrm{Ca}^{2+}$ e caixas de ovos representando as cadeias individuais de alginato, assim como a formação das cadeias associadas duas a duas entre si por um íon $\mathrm{Ca}^{2+}$, formando o gel (Figura 8).

Figura 8. Elaboração de modelo utilizando a caixa de ovo para representar as cadeias de alginato (a) Formação de um Gel (b).
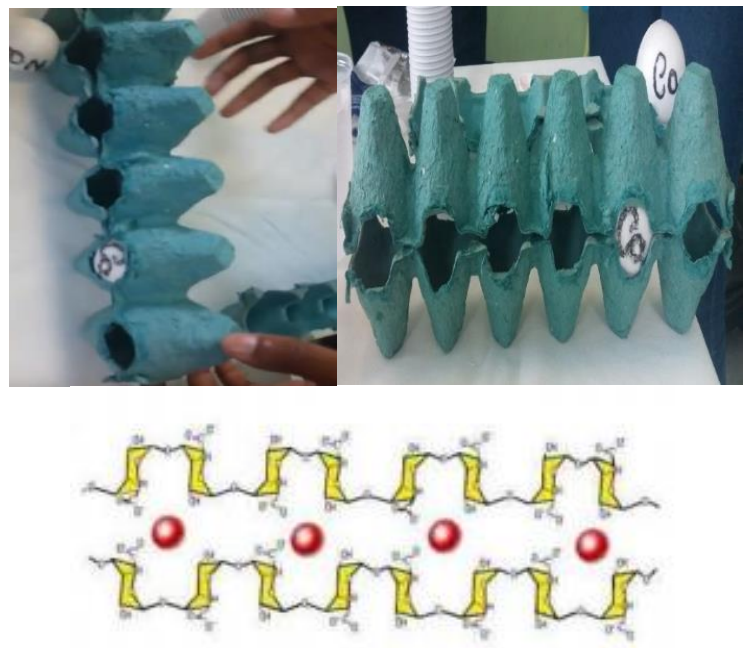

(a)

(b)

Fonte: ABRANTES (2014) 
Aula 9 - Avaliação formal - Aplicação da avaliação da aprendizagem através da prova bimestral e atividades aplicadas ao longo da SD.

Para análise da percepção dos alunos sobre a SD, foram avaliadas as respostas dos alunos a dois questionários:

1. Questionário de avaliação da atividade experimental com respostas baseadas em escala de Likert;

2. Questionário dissertativo sobre as percepções dos alunos sobre alimentação, GM e experimentação no ensino do tema ligações químicas.

Para a avaliação da Feira de Ciências, foram utilizadas transcrições de vídeos e análise da disposição da apresentação realizada e dos materiais utilizados durante a realização do experimento de esferificação.

Em relação ao questionário de avaliação da atividade experimental utilizando a escala de Likert, as respostas foram computadas e tabuladas. Foram realizadas leituras do grau de concordância dos alunos quanto às afirmativas feitas, aonde os resultados expressos foram calculados a partir dos escores de cada uma das dez assertivas segundo Tastle e Wierman, (2006). As afirmativas com menor discordância apresentam escores menores do que as afirmativas com maior concordância. De- 
terminou-se um peso $(\mathrm{P})$ diferente, sendo, respectivamente, para discordo totalmente (DT) valor igual a 1, discordo parcialmente (DP) valor igual a 2, não concordo nem discordo (NCND) valor igual a 3 , concordo parcialmente (CP) valor igual a 4 e concordo totalmente (CT) valor igual a 5. Identificou-se o escore para cada assertiva, aplicando a expressão:

Escore $=\left[\left(\mathrm{n}^{\circ} \mathrm{DT} / \mathrm{n}^{\circ}\right.\right.$ total $\left.\left.) \times 1\right)\right]+\left[\left(\mathrm{n}^{\circ} \mathrm{DP} / \mathrm{n}^{0}\right.\right.$ total $\left.\left.) \times 2\right)\right]+$

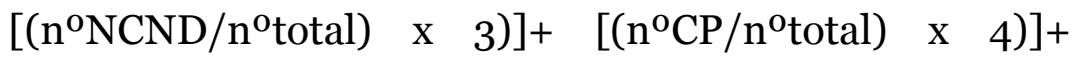
$\left[\left(\mathrm{n}^{\circ} \mathrm{CT} / \mathrm{n}^{\circ}\right.\right.$ total $\left.\left.) \times 5\right)\right]$

Fonte: Tastle e Wierman (2006).

A pesquisa pode ser caracterizada como qualitativa, pois a avaliação dos resultados obtidos a partir da SD fundamentou-se na interpretação das falas dos alunos envolvidos, buscando-se analisar suas percepções sobre as atividades realizadas.

\section{Resultados e Discussão}

Os escores obtidos para as assertivas do questionário de avaliação da atividade experimental foram, em ordem decrescente: Eu gostei da atividade que foi realizada (Escore 4,7); Me senti motivado(a) para realizar a atividade proposta (Escore 4,7); Realizar essa atividade fez com que eu entendesse a importância da Ciência dos alimentos (Escore 4,4); Realizar essa atividade fez com 
que eu entendesse a importância do estudo da gastronomia (Escore 4,3); A atividade me ajudou a fixar os conteúdos sobre ligações iônicas e covalentes (Escore 4,2); Me senti motivado(a) para realizar esta atividade em outros ambientes (Escore 4,2); A atividade me ajudou a aprender a trabalhar em equipe (Escore 4,0); A atividade me ajudou a relacionar o conteúdo de ligações químicas com o cotidiano (Escora 3,9); Me senti motivado(a) a pesquisar mais sobre gastronomia molecular (Escore 3,8); Realizar essa atividade aumentou minha vontade de estudar Química (Escore 3,5).

Os altos escores obtidos nas questões relativas ao interesse e sensação de motivação dos alunos pelas atividades realizadas na SD corroboram as afirmações realizadas por autores como Castoldi e Polinarski (2009) de que aulas que saem do formato clássico, muitas vezes denominadas de "diferentes", mobilizam a atenção e o interesse dos alunos. Neste caso, a mobilização parece ter se dado mais em relação aos aspectos tecnológicos abordados (entendimento da importância da Ciência dos Alimentos e da gastronomia) do que aos conteúdos curriculares de Química, que alcançou o menor escore entre as perguntas realizadas, embora os alunos reconheçam que a atividade auxiliou na fixação desses conteúdos. Assim, é possível inferir que a SD mobilizou a atenção dos alunos para os aspectos tecnológicos envolvidos na GM e da relação entre estes e os conteúdos estudados nas aulas de Química, promovendo, ainda de forma inicial, uma com- 
preensão das relações entre Ciência e Tecnologia, tal como esperado em uma proposta de atividade onde o enfoque CTS é incorporado sob a forma de pequenos estudos organizados ao redor de um tema unificador, conforme já explicitado anteriormente (SANTOS; MORTIMER, 2000).

O segundo questionário respondido pelos alunos tinha como objetivo coletar dados acerca da relação dos alunos com a alimentação e a gastronomia e da compreensão sobre os temas abordados na SD. Quando questionados sobre seus hábitos alimentares, $73 \%$ afirmaram consumir preferencialmente alimentos industrializados, especialmente os comercializados grandes redes de fast food, acessíveis ao público em estudo devido a condição econômica de suas famílias (classe média alta) e da localização da escola em uma região com estabelecimentos de fast food no entorno. Já em relação à pergunta se a participação na atividade havia promovido alguma mudança nos hábitos alimentares, 38,5\% afirmaram que mudaram de opinião sobre a escolha de alimentos; embora esse percentual represente pouco mais de um terço dos alunos envolvidos, demonstra a potencialidade da SD na promoção de mudanças procedimentais e atitudinais, que estão entre os objetivos de um ensino de Ciências pautado na contextualização e no enfoque CTS.

Ainda nesse mesmo questionário, ao serem questionados sobre a importância do conhecimento químico 
para o desenvolvimento das técnicas empregadas na GM, $69,2 \%$ dos alunos demonstraram uma apropriação, em seus discursos, dos termos científicos e tecnológicos trabalhados na SD, estabelecendo relações entre os saberes científicos e suas aplicações na GM. Esta análise é reforçada pela observação que $84,6 \%$ dos alunos utilizaram corretamente os conteúdos sobre Ligação Química na descrição do processo de esferificação quando solicitados a exporem o que aprenderam durante a atividade experimental. Assim, entende-se que a SD foi capaz de promover ações que criaram um ambiente propício à aprendizagem dos conceitos químicos trabalhados nas aulas e ao estabelecimento das relações entre esses conceitos e as técnicas de GM.

Para a análise da Feira de Ciências, partiremos de trechos das falas dos alunos que foram gravadas e transcritas pela professora pesquisadora.

Em relação à apresentação do conceito de GM para o público, o aluno 1 apresentou as relações estabelecidas entre conhecimentos científicos e técnicos com aspectos socioeconômicos e culturais nesse campo do saber.

Aluno 1: "[...] a gastronomia molecular é a Ciência dedicada ao estudo dos processos físicos e químicos relacionado à culinária, participando do processo dos ingredientes, do cozimento e resfriamento. Também estuda aspectos culturais, sociais e técnicas da culinária. O pú- 
blico que a gastronomia molecular atinge é a classe média e classe média alta, por ter poder aquisitivo maior [...]".

Assim, em sua fala, o aluno 1 explicitou uma das questões sociocientíficas pertinentes ao tema, que trata do acesso de um grupo restrito da sociedade às experiências culturais proporcionadas pela GM. Ele ainda complementa essa análise ao dizer, em seguida:

Aluno 1: “[...] A maioria das pessoas consomem alimentos mais baratos e que possuem agrotóxicos, não sendo a gastronomia molecular uma alimentação diária. Podemos indicar o programa Masterchef, que utiliza alimentos em sua maioria mais caros e técnicas que a população de renda mais baixa não pode consumir e nem realizar"

A partir dessa fala, observa-se que a SD promoveu, conforme preconizado pelo enfoque CTS, a criticidade do aluno em relação ao acesso à alimentação na sociedade brasileira, sendo que aos membros dos grupos menos favorecidos economicamente são destinados alimentos que os expõem a maiores riscos, ao mesmo tempo em que se restringe seu acesso a diferentes experiências culturais.

Em relação ao conteúdo específico da disciplina de Química, destacamos as seguintes falas: 
Aluno 2: "Vamos preparar as esferas de açaí. O açaí é batido com o alginato de sódio e por isso ele ficou com esta textura bem grossa. A gente usa a seringa para pegar a mistura $e$ adicionar ao cloreto de cálcio, que é quando junta o alginato de sódio e cloreto de cálcio formando as esferas. Só que o cloreto de cálcio é igual ao sal de cozinha, então deixa salgado, então devemos selecionar as esferas prontas e colocar na água filtrada para lavar, retirando o sal [...]”.

Aluno 3: "A esferificação inversa com o iogurte já apresenta uma quantidade de cálcio por apresentar leite, porém adicionamos mais cálcio para melhorar a textura. Ao juntar o alginato de sódio com o cálcio forma uma película pela troca de ions entre eles, que no caso são os íons sódio e cálcio [...]".

Pela análise da transcrição pode-se entender que os alunos compreenderam o uso de aditivos alimentares no encapsulamento através do uso de alginato, criando "caviares" pela técnica da esferificação básica e inversa. Ademais, suas explicações estão pautadas em conceitos de ligações químicas.

Pela análise das transcrições, observamos que os alunos compreenderam que nos alimentos e aditivos alimentares há compostos com ligações químicas de diferentes tipos. Assim, a experimentação foi importante como forma de abordar macroscopicamente aspectos relacionados aos conceitos teóricos abordados, tendo sido possível alcançar o objetivo do estabelecimento de relações entre o conteúdo de Ligação Química a aspectos tec- 
nológicos da GM. Ademais, ressaltamos que os alunos conseguiram compreender e discutir os fenômenos envolvidos utilizando a linguagem científica apropriada por eles ao longo das atividades realizadas.

A SD desenvolvida nesta pesquisa resultou em um produto educacional intitulado "Gastronomia Molecular no Ensino de Química: Uma proposta para o Ensino de ligações químicas por meio do enfoque CTS", que apresenta um total de 44 páginas. As atividades propostas encorajam a participação do discente a fim de desenvolver suas habilidades de argumentação e trazem propostas para que docentes possam se apropriar do material e utilizá-lo de maneira pertinente com seu públicoalvo. Além disso, a proposta é flexível para alterações metodológicas, podendo incluir ou suprimir textos, vídeos, experimentos e questionários.

\section{Conclusões}

A elaboração e aplicação de uma SD elaborada com base nos pressupostos do enfoque CTS tendo como temas a alimentação e a gastronomia molecular promoveram reflexões acerca das interrelações entre ciência, tecnologia e sociedade junto ao público alvo. Os alunos demonstraram compreender as relações que, na sociedade baseada no sistema capitalista, o acesso a alimentos de qualidade e a experiências culturais relacionadas à ali- 
mentação são determinados pelo poder aquisitivo dos diferentes grupos sociais.

A opção por construir uma SD relacionada à categoria 3 de Aikenhead (incorporação sistemática do conteúdo de CTS ao conteúdo programático) possibilitou sua aplicação na escola que serviu de campo de pesquisa, sem interferir na programação curricular prevista para a turma que participou das atividades realizadas. A utilização do aplicativo WhatsApp ampliou as possibilidades de utilização de materiais didáticos audiovisuais pela professora pesquisadora. Por outro lado, não se deve esquecer que essa opção metodológica implica em uma expansão da carga de trabalho docente, sendo importante cobrar dos estabelecimentos de ensino que proporcionem, aos professores, as condições adequadas para a realização de todas as atividades previstas dentro do horário de trabalho.

As atividades propostas, como as técnicas de esferificação direta e indireta, conduzem a experiências inovadoras, factíveis de serem conduzidas pelos alunos e ressaltando o papel de protagonismo que os alunos devem ocupar nas atividades de ensino e aprendizagem na Educação Básica. Ademais, essas atividades possibilitam a compreensão dos fenômenos que ocorrem durante a preparação desses alimentos, proporcionando não só a aprendizagem desses conceitos, mas também a sua incorporação nos discursos. Essas atividades, em seu conjunto, também são capazes de trabalhar os aspectos pro- 
cedimentais e atitudinais, estimulando a capacidade de argumentação e de análise crítica por parte dos estudantes.

A SD, como um todo, permite, ainda, que cada professor promova modificações que a adequem aos seus alunos, estimulando-os a refletirem sobre suas condições de vida em sociedade e sobre o acesso democrático a alimentos de qualidade e a experiências culturais que ampliem sua visão de mundo, contribuindo para a compreensão de seu papel enquanto sujeito histórico em uma sociedade desigual.

\section{Referências}

ABRANTES, G. M. M. S. Cozinha modernista: curso para introdução do ensino de novas técnicas culinárias na formação de cozinheiros. 219 f. Tese (Mestrado em Ciências Gastronômicas). Faculdade de Ciências e Tecnologia, Universidade NOVA de Lisboa. Lisboa. 2014.

ABREU, E. S. de et al. Alimentação mundial: uma reflexão sobre a história. Saúde e sociedade, v. 10, p. 3-14, 2001.

AIKENHEAD, G. What is STS science teaching? In: SOLOMON, J., AIKENHEAD, G. STS education: international perspectives on reform. New York: Teachers College Press, p.47-59, 1994 .

CASTOLDI, R.; POLINARSKI, C. A. A utilização de recursos didático-pedagógicos na motivação da aprendizagem. I Simpósio Nacional de Ensino de Ciência e Tecnologia, v. 684, 2009. 
FIRME, R. do N.; AMARAL, E. M. R. do. Analisando a implementação de uma abordagem CTS na sala de aula de química. Ciência \& Educação (Bauru), v. 17, n. 2, p. 383-399, 2011.

GIL, M. J. G. N. Gastronomia Molecular: uma abordagem de investigação para alunos do Básico e Secundário. 143 f. Tese (Mestrado em Química Industrial). Universidade da Beira Interior. 2010.

KIKUTI, E.; SOUZA, L. P. M. de; MOURA, T. de O. Divulgação e popularização científica da gastronomia. Revista Em Extensão, v. 17, n. 1, p. 225-242, 2018.

MARTINHO, T; POMBO, L. Potencialidades das TIC no ensino das Ciências Naturais-um estudo de caso. Revista Electrónica de Enseñanza de las Ciencias, v. 8, n. 2, p. 527-538, 2009.

MONTEIRO, C. A. A dimensão da pobreza, da desnutrição e da fome no Brasil. Estudos avançados, v. 17, n. 48, p. 7-20, 2003.

PALACIOS, E. M. G.; GALBARTE, J. C. G.; BAZZO, W. Introdução aos estudos CTS (Ciencia, Tecnología e Sociedade). Organización de Estados Iberoamericanos (OEI), 2005.

PROENÇA, R. P. da C. Alimentação e globalização: algumas reflexões. Ciência e Cultura, v. 62, n. 4, p. 43-47, 2010.

SANTOS, A. N. dos. Fome, educação e alimentação: proposta educativa na obra de Josué de Castro. 2012. 116f. - Dissertação (Mestrado) - Universidade Federal do Ceará, Programa de Pós-graduação em Educação Brasileira, Fortaleza (CE), 2012.

SANTOS, W. L. P. dos. Educação científica humanística em uma perspectiva freireana: resgatando a função do ensino de 
CTS. Alexandria: Revista de Educação em Ciência e Tecnologia, Florianópolis, v. 1, n. 1, p. 109-131, mar. 2008.

SANTOS, W. L. P. dos; MORTIMER, E. F. Uma análise de pressupostos teóricos da abordagem CTS (Ciência-TecnologiaSociedade) no contexto da educação brasileira. Ensaio Pesquisa em educação em ciências, v. 2, n. 2, p. 1-23, 2000.

TASTLE, W. J.; WIERMAN, M. J. An information theoretic measure for the evaluation of ordinal scale data. Behavior Research Methods, v. 38, n. 3, p. 487-494, 2006.

VALÉRIO, M.; BAZZO, W. A. O papel da divulgação científica em nossa sociedade de risco: em prol de uma nova ordem de relações entre ciência, tecnologia e sociedade. Revista de Ensino de Engenharia, v. 25, n. 1, p. 31-39, 2006.

ZABALA, A. A prática educativa: como ensinar; tradução Ernani F. da F. Rosa. Porto Alegre: Artmed, 1998. 